\title{
Rapid Detection of Flavobacterium psychrophilum Using Fluorescent Magnetic Beads and Flow Cytometry
}

\author{
Kyoko Hibi, Yasutoshi Yoshiura ${ }^{1}$, Hideki Ushio, \\ Huifeng Ren and Hideaki Endo* \\ Faculty of Marine Science, Tokyo University of Marine Science \& Technology, \\ 4-5-7 Konan, Minato-ku, Tokyo 108-8477, Japan \\ ${ }^{1}$ Aquatic Animal Health Division, National Research Institute of Aquaculture, \\ Fisheries Research Agency, 224-1 Hiruta, Tamaki, Mie 519-0423, Japan
}

(Received July 25, 2011; accepted February 9, 2012)

Key words: fluorescent magnetic beads, immunomagnetic separation, fish disease, Flavobacterium psychrophilum, harmful bacteria, detection

Flavobacterium psychrophilum has emerged as one of the most significant bacterial pathogens in salmonid aquaculture worldwide. We have been studying the detection of harmful bacteria using immunomagnetic separation and flow cytometry (FCM). In this study, we used fluorescent magnetic beads and 5-cyano-2,3-ditolyl tetrazolium chloride (CTC). Bacteria were specifically collected using fluorescent magnetic beads with only one antigen-antibody reaction. CTC turns into a red fluorescent formazan that is detectable by FCM. F. psychrophilum cells were stained with CTC and labeled with fluorescent magnetic beads. Double-stained bacteria (red fluorescence by CTC and green fluorescence from fluorescent magnetic beads) were detected by FCM. Bacterial cell numbers were determined by FCM and compared with those measured by a traditional colony counting method in the range of $10^{2}-10^{8}$ cells $/ \mathrm{ml}$. The FCM assay could provide a bacterial cell count within $1 \mathrm{~min}$ and the total assay time, including sample preparation, was less than $3 \mathrm{~h}$.

\section{Introduction}

The ability to determine the number of viable bacterial cells in water samples is very important in fishery industries, such as aquaculture, fish markets, and seafood products.

*Corresponding author: e-mail: endo@kaiyodai.ac.jp 
Measurements are made to determine total cell counts, total culturable cell counts, and the presence of specific viable bacterial cells, such as pathogens. After 20 years of intensive research, the most effective method of determining whether bacterial cells are alive or dead remains controversial. ${ }^{(1)}$ During the last two decades, various alternatives have been pursued, such as real-time monitoring methods for assessing viability ${ }^{(2)}$ and methods to determine the existence of injured and 'viable, but not culturable' cells exposed to stressors. ${ }^{(3,4)}$

Cell-specific assays to detect the respiratory activity of bacteria with the use of different tetrazolium salts have been developed. Tetrazolium dyes are reduced from a colorless complex to a brightly colored, intracellular formazan precipitate by components of the electron transport system and/or a variety of dehydrogenase enzymes present in active bacterial cells. Because electron transport is directly related to cellular energy metabolism in respiring cells, the ability of cells to reduce tetrazolium compounds is considered to be an indicator of bacterial activity. An alternative approach is the use of the redox dye 5-cyano-2,3-ditolyl tetrazolium chloride (CTC). CTC is reduced by bacteria to a water-insoluble, red fluorescent formazan product, which allows for the quantification of the metabolic activity of bacteria under both aerobic and various anaerobic conditions. ${ }^{(5,6)}$ Several factors, however, can affect CTC reduction during incubation. ${ }^{(7-9)}$ Although CTC counts are commonly determined by flow cytometry (FCM), ${ }^{(10-12)}$ epifluorescence microscopy can also be used to overcome the rapid fading of the fluorescence signal, ${ }^{(13)}$ yielding equal or higher counts. ${ }^{(14)}$

FCM has become more popular and offers the ability to analyze individual cells at numbers that are more representative of nature.(15) FCM allows for the rapid and simultaneous measurement of various cell parameters with a precision of a few percent. FCM is not adapted to detect event rates, however, because it is difficult to detect fewer than 100 cells $/ \mathrm{ml}$, which is still 10 - to 100 -fold better than current microscopy procedures. Thus, concentration technology is needed to increase the density of the cells.

One alternative method for rapidly concentrating samples uses antibody-coated magnetic beads and immunomagnetic separation (IMS) to concentrate target bacteria that are then measured using FCM or another device. ${ }^{(16-18)}$ IMS with a specific antibody is a powerful method of detecting target microbes from heterogeneous microbial suspensions. IMS depends on the interaction between antibodies bound to cell surface antigens and paramagnetic beads. Samples drawn and collected by IMS are concentrated. When using IMS, the resulting sample concentration can be tuned. An advantage of IMS is to be able to wash bacteria collected once. It is because impurities are removed by washing the sample. We have quantified harmful bacteria using immunomagnetic beads and fluorescent dye-labeled antibody. ${ }^{(19,20)}$ The antibody conjugated to the fluorescent dye is used to specifically label the target bacteria. The magnetic bead, which is attached to the antibody, is then used to isolate the target bacteria from the rest of the sample. A concentrated sample of the target bacteria is thus produced.

Flavobacterium psychrophilum causes a severe disease in fish, particularly farmed rainbow trout (Oncorhynchus mykiss), throughout the world. It can be transmitted horizontally indirectly through the water and directly by fish-to-fish contact. Over the past 10 years in many parts of Europe, rainbow trout fry syndrome and bacterial cold 
water disease caused by $F$. psychrophilum have become the most serious bacterial fish diseases. Current treatments of this problem include raising the water temperature and administering medicine. The disease should be treated as early as possible to prevent or delay the spread.

The purpose of the present study was to develop a method of rapidly detecting viable bacteria using a combination of CTC, fluorescent magnetic beads, and FCM. The bacterial viability can be determined using CTC and the magnetic beads to be isolated. Then the measurement sensitivity is improved by collecting bacteria of the target and the FCM allows us to determine how much F. psychrophilum is in the sample.

\section{Materials and Methods}

\subsection{Materials}

The polymer sample used in this study was commercial water-soluble carbodiimide (WSC) and CTC obtained from Dojindo (Kumamoto, Japan). Tryptone and yeast extract were obtained from Difco Laboratories (Detroit, MI). Sodium acetate and calcium chloride were obtained commercially and were of analytical reagent grade. Bonito extract was obtained from Wako Pure Chemical Industries, Ltd (Osaka, Japan). Fluorescent magnetic beads were obtained from Chemicell (Berlin, Germany). Microcon was obtained from Millipore (Billerica, MA). Rabbit anti-F. psychrophilum serum was manufactured by Kitayama Labs Co. Ltd (Nagano, Japan).

\subsection{Microorganisms and culture}

F. psychrophilum FPC 840, Escherichia coli IM 12119, Pseudomonas fluorescens IAM12022, Lactococcus garvieae H 9507, Staphylococcus aureus, and Vibrio sp. were used as model microorganisms. F. psychrophilum FPC 840 was cultured in a cytophaga broth containing $0.5 \mathrm{~g} / 1$ tryptone, $0.5 \mathrm{~g} / 1$ yeast extract, $0.2 \mathrm{~g} / 1$ beef extract, and $0.2 \mathrm{~g} / \mathrm{l}$ sodium acetate trihydrate, at $\mathrm{pH} 7.2$ at approximately $15^{\circ} \mathrm{C}$ for $3 \mathrm{~d}$. E. coli, P. fluorescens, $S$. aureus, and $L$. garvieae were cultured overnight in Luria Bertani medium consisting of $10 \mathrm{~g} / \mathrm{l}$ tryptone, $5 \mathrm{~g} / \mathrm{l}$ yeast extract, and $5 \mathrm{~g} / 1 \mathrm{NaCl}$ using a shaking flask at $25^{\circ} \mathrm{C}$ for $20 \mathrm{~h}$.

\subsection{CTC staining conditions}

These studies were performed with cultures of the above-mentioned strains grown in cytophaga broth $\left(15^{\circ} \mathrm{C}, 48 \mathrm{~h}\right)$ and washed in phosphate buffer $\left(\mathrm{PB} ; 10 \mathrm{mM} \mathrm{Na} \mathrm{HPO}_{4}, 10\right.$ $\mathrm{mM} \mathrm{NaH} \mathrm{PO}_{4}, \mathrm{pH}$ 7.2). A $20 \mathrm{mM} \mathrm{CTC}$ stock solution in distilled water was prepared and stored at $4{ }^{\circ} \mathrm{C}$ until use. F. psychrophilum was washed in $\mathrm{PB}$, and after discarding the supernatant solution, equal amounts of $\mathrm{PB}$ and medium were added to bring the concentration of CTC to $0.2 \mathrm{mM}$. The reduction of CTC to the fluorescent formazan was monitored by $\mathrm{FCM}$ after incubating the bacteria at $15^{\circ} \mathrm{C}$ and agitating with either a rotating cultivator (Rotate RT-50, Koshigaya, Japan) or a micromixer (Micromixer E-36, Koshigaya, Japan). Samples of the culture were obtained every $30 \mathrm{~min}$ for $3 \mathrm{~h}$. The percentage of cells with reduced CTC was also determined for cultures containing no medium (starved cultures). 


\subsection{Preparation of fluorescent magnetic bead-antibody conjugates}

The antibodies were ultrafiltered to facilitate an efficient reaction between the antibodies and magnetic beads. A sample solution containing anti-F. psychrophilum rabbit IgG antibody $(200 \mu \mathrm{l})$ and WSC buffer $(100 \mu \mathrm{l})$ were added to a filtration tube. WSC was used as a cross-linking agent. This mixture was mixed thoroughly by pipetting and centrifuged at $8,000 \mathrm{~g}$ for $10 \mathrm{~min}$. More WSC buffer $(100 \mu \mathrm{l})$ was added to the filtration tube and the mixture was centrifuged again at $8,000 \mathrm{~g}$ for $10 \mathrm{~min}$. The fluorescent magnetic bead $(10,50,100,150$, and $200 \mathrm{ml})$ solution was added to the $\mathrm{IgG}$ antibody concentrated in the filtration tube. The concentration of the fluorescent magnetic beads was $2.25 \mathrm{~g} / \mathrm{cm}^{3}$. The magnetic beads are coated in such a way that the carboxyl group is free to react with the amino group of the antibody and the WSC buffer. The carbodiimides react with the terminal carboxylate-groups of the magnetic beads to form highly reactive O-acylisourea derivatives, which then readily react with the amino groups of the ligands. This binary covalent binding system thus guarantees good reproducibility of the immobilization. This sample was incubated at $37^{\circ} \mathrm{C}$ for $2 \mathrm{~h}$ after mixing thoroughly by pipetting. WSC buffer $(190 \mu \mathrm{l})$ was added to the sample and the sample was stored at 0 to $5^{\circ} \mathrm{C}$.

\subsection{Flow cytometry analysis}

A Beckman Coulter Epics XL flow cytometer equipped with an air-cooled $488 \mathrm{~nm}$ argon-ion laser at $15 \mathrm{mV}$ was set up with the standard configuration (Beckman Coulter, Fullerton, CA). Two fluorescence intensities (FL) were measured simultaneously. Fluorescence emission was measured in four channels: FL1, wavelength 490-550 nm; FL2, 570-580 nm; FL3, 600-620 nm; and FL4, 665-685 nm. The green emission (FL1) from the fluorescent magnetic beads was collected with a $525 \mathrm{~nm}$ band-pass filter. The red emission (FL4) from CTC was collected with a $675 \mathrm{~nm}$ band-pass filter. The stop time for the passage of the sample was set at $60 \mathrm{~s}$, and the event number (number of particles passing through the laser beam) was measured as the number of bacteria.

The function of "Compensation" is provided in FCM. In the FCM determination, the emission spectra from the two fluorescent probes overlap, thus requiring compensation. Spectral overlap between green fluorescence and red fluorescence produces light that is detected by both FL1 and FL4 detectors. The amount of green fluorescence detected by the FL4 detector (i.e., the red fluorescence detector) was regarded as excess fluorescence and was subtracted from the signal. This amount of spectral overlap was corrected by subtracting the percentage from the total green fluorescence pulse generated by the FL1 detector. Therefore, the green fluorescence produced by the fluorescent magnetic beads detected by the FL4 detector was considered to be interference. By subtracting a percentage of the total green fluorescence pulse from the total pulse generated by the FL4 detector (CTC plus fluorescent magnetic bead fluorescence), we obtained a redfluorescence-only pulse. Thus, a double measurement of the particle with both red and green fluorescence was prevented.

\subsection{CTC-fluorescence double staining of magnetic beads}

Cells with red fluorescence from CTC were determined by FCM to confirm that the cells were stained. Magnetic beads prepared beforehand $(5,10,30,50,70$, and $100 \mu \mathrm{l})$ 
were added to the stained cells. The cells were mixed well and incubated at room temperature for $10,20,40,60$, or $80 \mathrm{~min}$. The antibody-coated fluorescent magnetic beads and F. psychrophilum cells were antigen-antibody reacted. After washing twice to avoid nonspecific binding of cells, the magnetically coated cells were immobilized with the magnet and resuspended in PB. A total of $1 \mathrm{ml}$ of $F$. psychrophilum suspension containing $10^{4}$ to $10^{8}$ cells $/ \mathrm{ml}$ was isolated and then added to $1 \mathrm{ml}$ of $\mathrm{PB}$, and $20 \mathrm{ml}$ of $10^{1}$ to $10^{5}$ cells $/ \mathrm{ml} \mathrm{F}$. psychrophilum suspension was isolated and then added to $200 \mu \mathrm{l}$ of PB. High concentrations $\left(10^{4}\right.$ to $10^{8}$ cells $\left./ \mathrm{ml}\right)$ of $F$. psychrophilum were not concentrated, and low concentrations $\left(10^{1}\right.$ to $10^{5}$ cells $\left./ \mathrm{ml}\right)$ of $F$. psychrophilum were concentrated 100-fold. These cell suspensions were used for the FCM analyses.

\section{Results and Discussion}

\subsection{Relationship between CTC staining condition and time}

The frequency of cells containing reduced CTC was dependent on the probe concentration and nutrient addition. The CTC concentration was adjusted to $2 \mathrm{mM}$ (final concentration), on the basis of the report of Yamaguchi et al. ${ }^{(12)}$ For E. coli cultures, tryptone soya broth was used for CTC assays, ${ }^{(13)}$ but we chose cytophaga broth, which is the medium used for $F$. psychrophilum. The relationship between CTC staining condition and time is shown in Fig. 1. The staining rate increased with an increase in time under all three conditions. When the micromixer was used to agitate the culture, the staining rate reached $94.9 \%$ at $120 \mathrm{~min}$ and $96.8 \%$ at $180 \mathrm{~min}$. The staining rate reached a plateau by 120 min (Fig. 1). The best CTC staining condition was considered

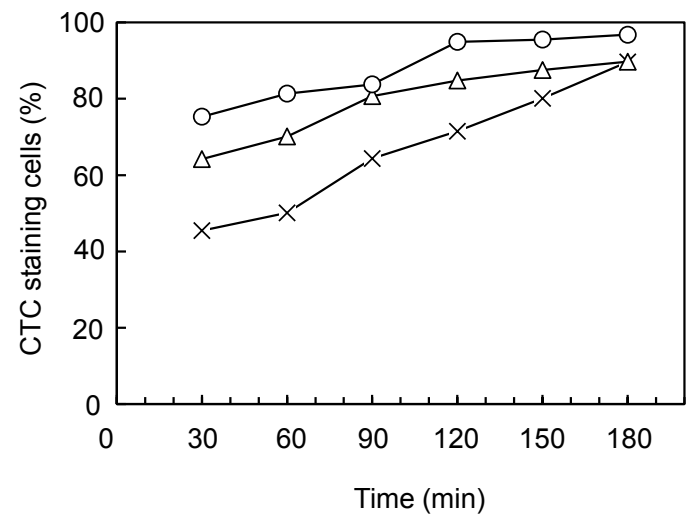

Fig. 1. CTC staining conditions and time. Circles are for CTC staining ratio for bacteria incubated with $600 \mathrm{rpm}$ agitation by a micromixer every $30 \mathrm{~min}$ for $3 \mathrm{~h}$. Triangles are for CTC staining ratio for bacteria incubated with $10 \mathrm{rpm}$ agitation by a rotator every $30 \min$ for $3 \mathrm{~h}$. Crosses are for CTC staining ratio for bacteria incubated with standing culture every $30 \mathrm{~min}$ for $3 \mathrm{~h}$. 
to be agitation with the micromixer for $120 \mathrm{~min}$. The F. psychrophilum concentration of the sample used for this experiment was $10^{6} \mathrm{CFU} / \mathrm{ml}$ (CFU: colony forming units). When a lower concentration of bacteria was stained with CTC, the ratio of stained cells decreased somewhat (data not shown). CTC is reported to have toxic effects on bacterial metabolism. ${ }^{(21)}$ Although sodium chloride has been used in CTC assays of Lactobacillus sakeii and Listeria monocytogenes cultures, ${ }^{(22,23)} \mathrm{F}$. psychrophilum does not grow in medium containing $2 \%$ salt. ${ }^{24)}$ Therefore, we did not add $\mathrm{NaCl}$ to the medium for the CTC assay of F. psychrophilum. When the bacteria were killed using formalin, CTC did not induce a red fluorescence. Therefore, the CTC assay allowed us to distinguish between viable and dead F. psychrophilum.

\subsection{Fluorescence scattergrams for F. psychrophilum}

F. psychrophilum cells suspended in PB were analyzed by FCM after staining with CTC [Figs. 2(b) and 2(d); red fluorescence] and/or fluorescent magnetic beads [Figs. 2(c) and 2(d); green fluorescence]. Results for unstained F. psychrophilum measured by FCM are shown in Fig. 2(a). Cells stained with only CTC exhibit only red fluorescence. In the FCM determination, the emission spectra from the two fluorescent probes overlap, thus requiring compensation. Spectral overlap between green fluorescence and red

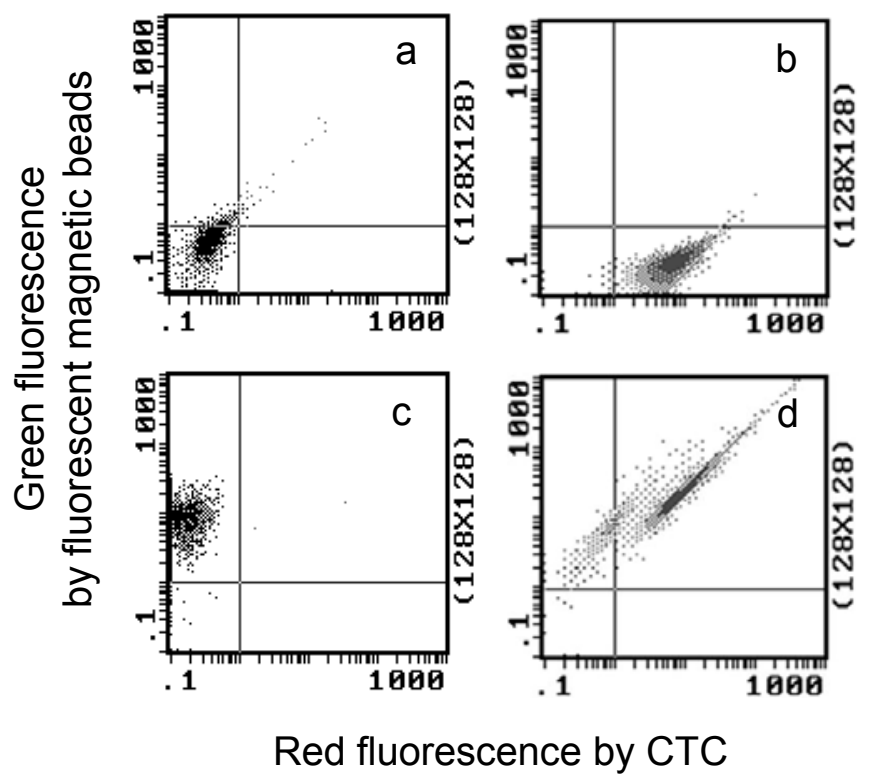

Fig. 2. Flow cytometric analysis of fluorescence staining cells and fluorescent magnetic beads. (a) F. psychrophilum cells suspension, (b) CTC stained cells, (c) fluorescent magnetic beads, (d) fluorescent magnetic beads and CTC double-stained cells. 
fluorescence produces light that is detected by both FL1 and FL4 detectors. The amount of green fluorescence detected by the FL4 detector (i.e., the red fluorescence detector) was regarded as excess fluorescence and was subtracted from the signal. This amount of spectral overlap was corrected by subtracting the percentage from the total green fluorescence pulse generated by the FL1 detector. Therefore, the green fluorescence produced by the fluorescent magnetic beads detected by the FL4 detector was considered to be interference. By subtracting the percentage of the total green fluorescence pulse from the total pulse generated by the FL4 detector (CTC plus fluorescent magnetic beads fluorescence), we obtained a red-fluorescence-only pulse. After measuring CTC-stained bacteria and fluorescent magnetic beads alone, a "compensation system" for the FCM was applied, and the signals shown in Fig. 2(d) were calculated. CTC-stained bacteria were added to the fluorescent magnetic beads. Fluorescent magnetic beads with the antigen-antibody were reacted with $F$. psychrophilum because the magnetic beads were conjugated with anti- $F$. psychrophilum antibody. After the reaction, a neodymium magnet was placed near the sample. The sample solution was reddish brown owing to the mixture of CTC-stained bacteria and fluorescent magnetic beads. When the neodymium magnet came close to the sample, the reddish-brown particles were drawn to the magnet, and the solution became transparent. The supernatant of this sample was discarded, and after washing twice with PB, PB was added to the sample, and the sample was measured by FCM [Fig. 2(d)]. There were cells with both green and red fluorescence. There were particles in the area with only green fluorescence, which represent fluorescent magnetic beads that did not react with the cells. These results indicated that F. psychrophilum could be measured using fluorescent magnetic beads.

\subsection{Antibody specificity}

The specificity of this method using CTC staining and fluorescent magnetic beads was also examined for E. coli, P. fluorescens, L. garvieae, S. aureus, and Vibrio sp. (Fig. 3). The concentration of each species was $10^{6} \mathrm{CFU} / \mathrm{ml}$. These bacteria were stained with CTC in accordance with previous reports. ${ }^{(6)}$ After confirming that the cells were stained using FCM, the fluorescent magnetic beads were added. The cells were magnetically separated with the neodymium magnet, and CTC-stained bacteria that had not bound to the magnetic beads were washed out. The antibody reacted with F. psychrophilum, with $90 \%$ of the cells being detected, but it did not react with E. coli, P. fluorescens, $L$. garvieae, or S. aureus; less than $8 \%$ of these cells were detected.

CTC-stained bacteria (F. psychrophilum) were added to fluorescent magnetic beads that were not conjugated with antibodies and then incubated for $1 \mathrm{~h}$. Most of the CTCstained bacteria were washed out of the sample because there was no antibody. A small number of bacteria were still detected, however, owing to the nonspecific adsorption of the bacteria to the fluorescent magnetic beads (data not shown). Washing the sample twice was critical to prevent the nonspecific adsorption of the bacteria.

\subsection{Determination of optimal amount of antibody}

The amount of antibody added to the magnetic beads was examined (Fig. 4). The antibody was conjugated with fluorescent magnetic beads to determine the amount of 


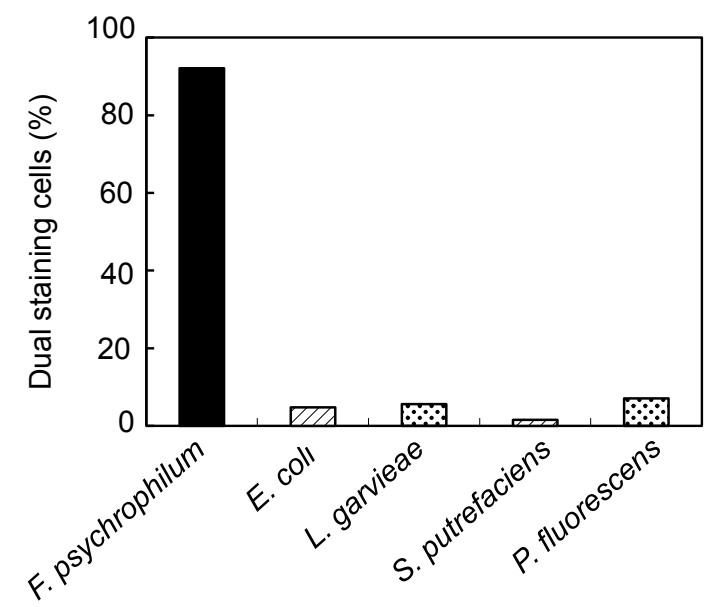

Fig. 3. Antibody specificity to $F$. psychrophilum and other bacterial species. Each cell concentration was prepared to $1 \times 10^{6}-6 \times 10^{6}$ cells $/ \mathrm{ml}$. The FCM assay conditons were the same as in the case of Fig. 1.

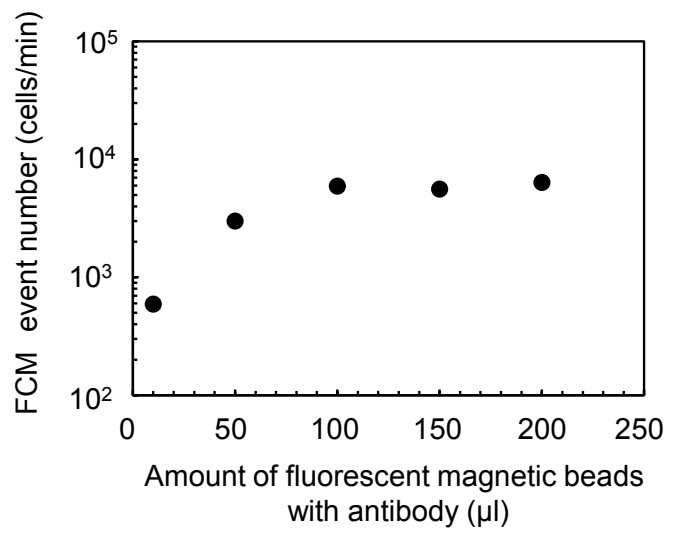

Fig. 4. Effect of amount of antibody on bacterial detection $(n=3)$. The FCM assay conditions were the same as in the case of Fig. 1 .

bacteria. Different amounts of antibody $(10,50,100,150$, and $200 \mu \mathrm{l})$ were added to the fluorescent magnetic beads. The concentration of the antibody solution was 0.5 $\mathrm{mg} / \mathrm{ml}$. Immunomagnetic beads conjugated with antibody were reacted with the $F$. psychrophilum suspension. When the amount of antibody was 10 or $50 \mu 1$, the results of the FCM measurements were low. We assumed that not all fluorescent magnetic beads were conjugated with the antibody because the amount of antibody was smaller than that 
of the magnetic beads. When the amount of antibody exceeded $100 \mu 1$, the results of the FCM measurements reached a plateau, indicating that the maximum number of beads had conjugated with the antibody. The optimal amount of antibody was determined to be $100 \mu 1$.

\subsection{Determination of optimal amount of antibody-conjugated magnetic beads}

The effect of various amounts of fluorescent magnetic beads conjugated with the antibody on the FCM detection of bacteria was examined (Fig. 5). Different amounts of immunomagnetic beads conjugated with the antibody $(5,10,30,50,70$, and $100 \mu \mathrm{l})$ were added to the $F$. psychrophilum suspension. The concentration of bacteria used was $10^{6} \mathrm{CFU} / \mathrm{ml}$. When $5 \mu \mathrm{l}$ of immunomagnetic beads was added, the results of the FCM measurements were low. We assumed that not all of the bacteria had reacted with the magnetic beads because the amount of immunomagnetic beads added was less than that of bacteria. When we added $10 \mu \mathrm{l}$ of the immunomagnetic beads, the results of the FCM measurements increased. The response reached a plateau at $10 \mu \mathrm{l}$. The optimal amount of immunomagnetic beads used was $10 \mu \mathrm{l}$.

We added magnetic beads $(10 \mathrm{ml})$ to bacteria of $10^{6} \mathrm{CFU} / \mathrm{ml}$ to examine how many bacteria react with one bead. The suspension of post-IMS magnetic beads and suspension with papain added to the post-IMS magnetic beads were each transferred onto plates to determine the number of CFUs by plate counting. Suspension with papain buffer (concentration of $1.08 \mathrm{mg} / \mathrm{ml}$ ) added to the post-IMS magnetic beads had twice as many colonies than the suspension of only post-IMS magnetic beads. Papain buffer helped the antigen detach from the antibody. ${ }^{(24)}$ Therefore, about one or two bacteria are reactive to one magnetic bead.

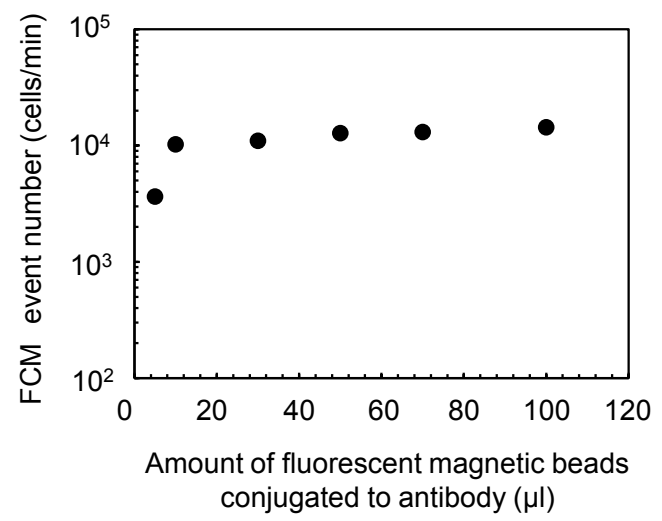

Fig. 5. Effect of fluorescent magnetic beads conjugated with antibody on bacterial detection $(n=3)$. The FCM assay conditions were the same as in the case of Fig. 1. 


\subsection{Determination of optimal incubation time}

The antigen-antibody reaction time of the immunomagnetic beads and bacteria was examined (Fig. 6). Immunomagnetic beads $(10 \mu \mathrm{l})$ were added to a $1 \mathrm{ml}$ sample of $F$. psychrophilum, and the mixture was incubated for 10, 20,40,60, or $80 \mathrm{~min}$. Figure 6 shows that the FCM event number increased with an increase in time within the range of 0 to $40 \mathrm{~min}$. When the incubation time exceeded $40 \mathrm{~min}$, the FCM count reached a plateau and the counts at 60 and $80 \mathrm{~min}$ were almost the same. Therefore, the incubation time was set at $60 \mathrm{~min}$.

\subsection{Correlation between FCM and colony-counting methods}

Suspensions of $F$. psychrophilum cells at $10^{2}$ to $10^{8} \mathrm{CFU} / \mathrm{ml}$ were incubated with CTC. CTC-stained cells were not washed, and a $10 \mu \mathrm{l}$ solution containing fluorescent beads was added. After incubation for $60 \mathrm{~min}$ while standing at room temperature, separated and washed cells were resuspended in PB. Only magnetic separation was used for the high-concentration samples $\left(10^{5}-10^{8} \mathrm{CFU} / \mathrm{ml}\right.$; high concentration). After the magnetic separation, the supernatant was discarded while the bacteria were immobilized by the magnet, and an amount of PB equal to that of the discarded solution was added. Therefore, there was no change in the sample concentration. Magnetic separation and concentration were applied to the low-concentration samples $\left(10^{2}-10^{5} \mathrm{CFU} / \mathrm{ml}\right.$; low concentration). After the magnetic separation, the supernatant was discarded while the bacteria were immobilized with the magnet, and PB was added. The amount of PB added was $1 / 100$ of the amount of the discarded sample. The concentration of the sample was therefore increased 100-fold. Figure 7 shows the measurement results of the prepared sample. In the high-concentration samples, magnetic separation alone was useful for isolating the cells. When the cells were not concentrated, however, densities of less than $10^{4} \mathrm{CFU} / \mathrm{ml}$ could not be measured. When the cells were concentrated,

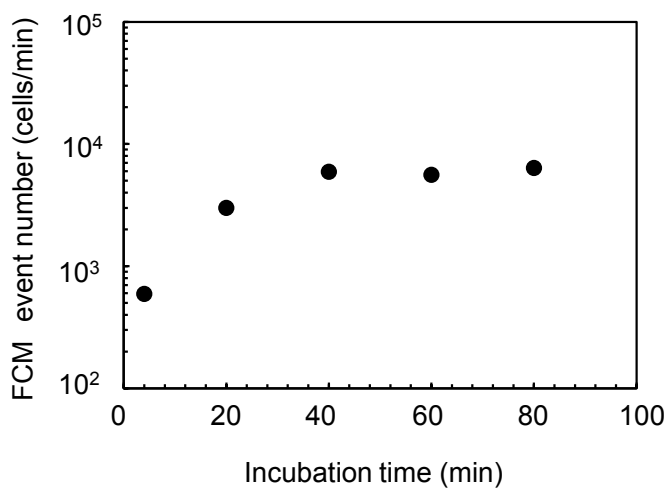

Fig. 6. Effect of incubation time on bacterial detection $(n=3)$. The FCM assay conditions were the same as in the case of Fig. 1. 

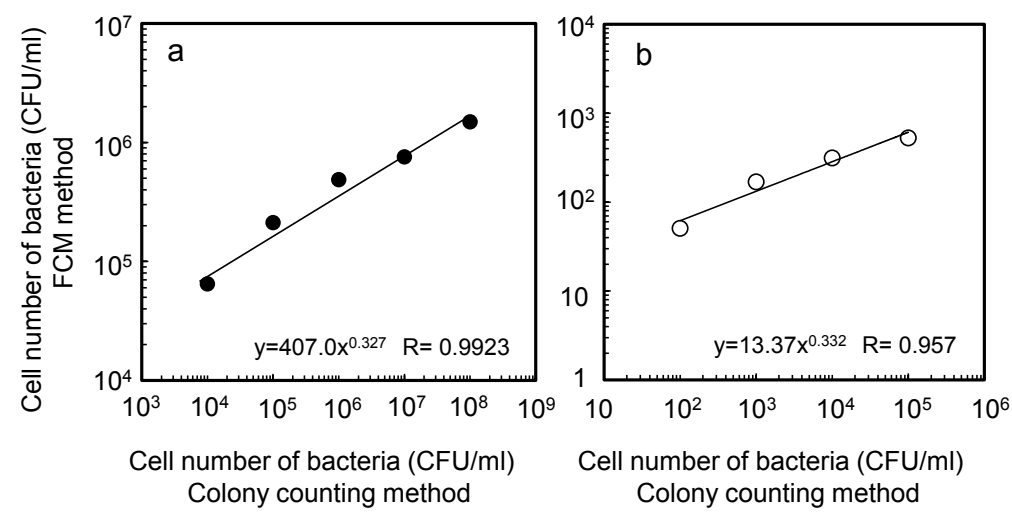

Fig. 7. Correlation between the proposed FCM method and colony counting method. (a) High concentration $10^{4}-10^{8} \mathrm{CFU} / \mathrm{ml}$. (b) Low concentration $10^{2}-10^{5} \mathrm{CFU} / \mathrm{ml}$. The FCM assay conditions were the same as in the case of Fig. 1. CFU: colony forming units.

however, detection over a wide range of densities was possible. There was a strong correlation between the values determined by the FCM method and by the colonycounting method for both the low and high concentrations (low concentration $R=0.9846$; high concentration $R=0.9923$ ).

The combination of the CTC fluorescence probe with the fluorescent magnetic beads allowed for the quantification of harmful viable bacteria. It should also be possible to use magnetic beads with different fluorescent properties conjugated to different antibodies to measure two viable bacteria. This method can be used in environmental studies as well as in various medical fields and the food industry. For example, this method can be applied to the problem of ballast water contamination, which is an international problem of marine pollution caused by ballast water and tank sediments.

\section{Conclusions}

We determined the optimum conditions for CTC staining of $F$. psychrophilum to distinguish between viable and dead F. psychrophilum. Furthermore, we developed a new assay method for the rapid determination of viable $F$. psychrophilum. The calibration curve for F. psychrophilum was linear in the ranges of $10^{5}$ to $10^{9}$ and $10^{2}$ to $10^{5} \mathrm{CFU} / \mathrm{ml}$. In this assay method, a CTC-fluorescent probe and an IMS technique with fluorescent magnetic beads combined with FCM were used to detect viable $F$. psychrophilum.

\section{Acknowledgments}

This research was supported in part by a Grant-in-Aid for Scientific Research (B) from The Ministry of Education, Culture, Sports, Science and Technology. 


\section{References}

1 M. R. Barer and C. R. Harwood: Adv. Microb. Physiol. 41 (1999) 93.

2 S. V. Sidorowicz and T. N. Withmore: J. IWEM 9 (1995) 92.

3 D. B. Rozak, D. J. Grimes and R. R. Colwell: Can. J. Microbiol. 30 (1984) 334.

4 D. M. Ward, R. Weller and M. M. Bateson: Nature 345 (1990) 63.

5 J. Porter, D. Deere, R. Pickup and C. Edwards: Cytometry 23 (1996) 91.

6 V. K. Bhupathiraju, M. Hernandez, D. Landfear and L. Alvarez-Cohen: J. Microbiol. Methods 37 (1999) 231.

7 J. J. Smith and G. A. McFeters: J. Appl. Bacteriol. 80 (1996) 209.

8 M. E. Sieracki, T. L. Cucci and J. Nicinski: Appl. Environ. Microbiol. 65 (1999) 2409.

9 C. G. Gruden, S. Fevig, M. Abu-Dalo and M. Hernandez: J. Microbiol. Methods 52 (2003) 59.

10 R. Lopez-Amoros, S. Castel, J. Comas-Riu and J. Vives-Rego: Cytometry 29 (1997) 298.

11 D. A. Veal, D. Deere, B. Ferrari, J. Piper and P. V. Attfield: J. Immunol. Methods 243 (2000) 191.

12 N. Yamaguchi, M. Sasaki, M. Yamanaka and M. Nasu: Cytometry A 54A (2003) 27.

13 P. B. Hatzinger, P. Palmer, R. L. Smith, C. T. Penarrieta and T. Yoshinari: J. Microbiol. Methods 52 (2003) 47.

14 S. Bartosch, R. Mansch, K. Knotzsch and E. Bock: J. Microbiol. Methods 52 (2003) 75.

15 H. Endo, J. Nakayama, T. Hayashi and E. Watanabe: Fish. Sci. 63 (1997) 1024.

16 L. Chen, L. Deng, L. Lui and Z. Peng: Biosens. Bioelectron. 22 (2007) 1487.

17 S. Sethi, M. T. Gore and K. K. Sethi: J. Microbiol. Methods 70 (2007) 328.

18 K. Hibi, A. Abe, E. Ohashi, K. Mitsubayashi, H. Ushio, T. Hayashi, H. Ren and H. Endo: Anal. Chim. Acta 573-574 (2006) 158.

19 K. Hibi, K. Mitsubayashi, H. Fukuda, H. Ushio, T. Hayashi, H. Ren and H. Endo: Biosens. Bioelectron. 22 (2007) 1916.

20 K. Hibi, H. Ushio, H. Fukuda, K. Mitsubayashi, T. Hayashi, H. Ren and H. Endo: Anal. Bioanal. Chem. 391 (2008) 1147.

21 S. Ullrich, B. Karrasch, H. G. Hoppe, K. Jeskulke and M. Mehrens: Appl. Environ. Microbiol. 62 (1996) 4587.

22 V. Besnard, M. Federighi and J. M. Cappelier: Food Microbiol. 17 (2000) 697.

23 F. Leroy and L. De Vuyst: Int. J. Food Microbiol. 100 (2005) 141.

24 J. M. Perez, F. J. Simeone, Y. Saeki, L. Josephson and R. Weissleder: J. Am. Chem. Soc. 125 (2003) 10192. 